Supplementary Materials for:

Evaluating the degree of oxygenation of organic aerosol during foggy and hazy days in Hong Kong using high-resolution time-of-flight aerosol mass spectrometry (HR-ToF-AMS)

$$
\text { Y.J. Li }{ }^{1} \text {, B.Y.L. Lee }{ }^{1} \text {, J.Z. Yu }{ }^{1,2} \text {, N.L. } \mathrm{Ng}^{3} \text { and C.K. Chan }{ }^{1,4}
$$

${ }^{1}$ Division of Environment, Hong Kong University of Science and Technology, Hong Kong, China

${ }^{2}$ Department of Chemistry, Hong Kong University of Science and Technology, Hong Kong, China

${ }^{3}$ School of Earth and Atmospheric Sciences, Georgia Institute of Technology, Atlanta, Georgia, USA

${ }^{4}$ Department of Chemical and Biomolecular Engineering, Hong Kong University of Science and Technology, Hong Kong, China

Manuscript submitted to Atmospheric Chemistry and Physics, 28 ${ }^{\text {th }}$, Jan, 2013

Correspondence to: C.K. Chan (keckchan@ ust.hk) 


\section{Supporting graphs}



FIGURE S1. Visibility, wind vector, $\mathrm{RH}$, and estimated liquid water content in fine particles $\left(\mathrm{LWC}_{\mathrm{fp}}\right)$, as well as selected pictures taken during the campaign. Pictures were taken with an automatic camera on an island approximately $20 \mathrm{~km}$ south of the sampling site. 

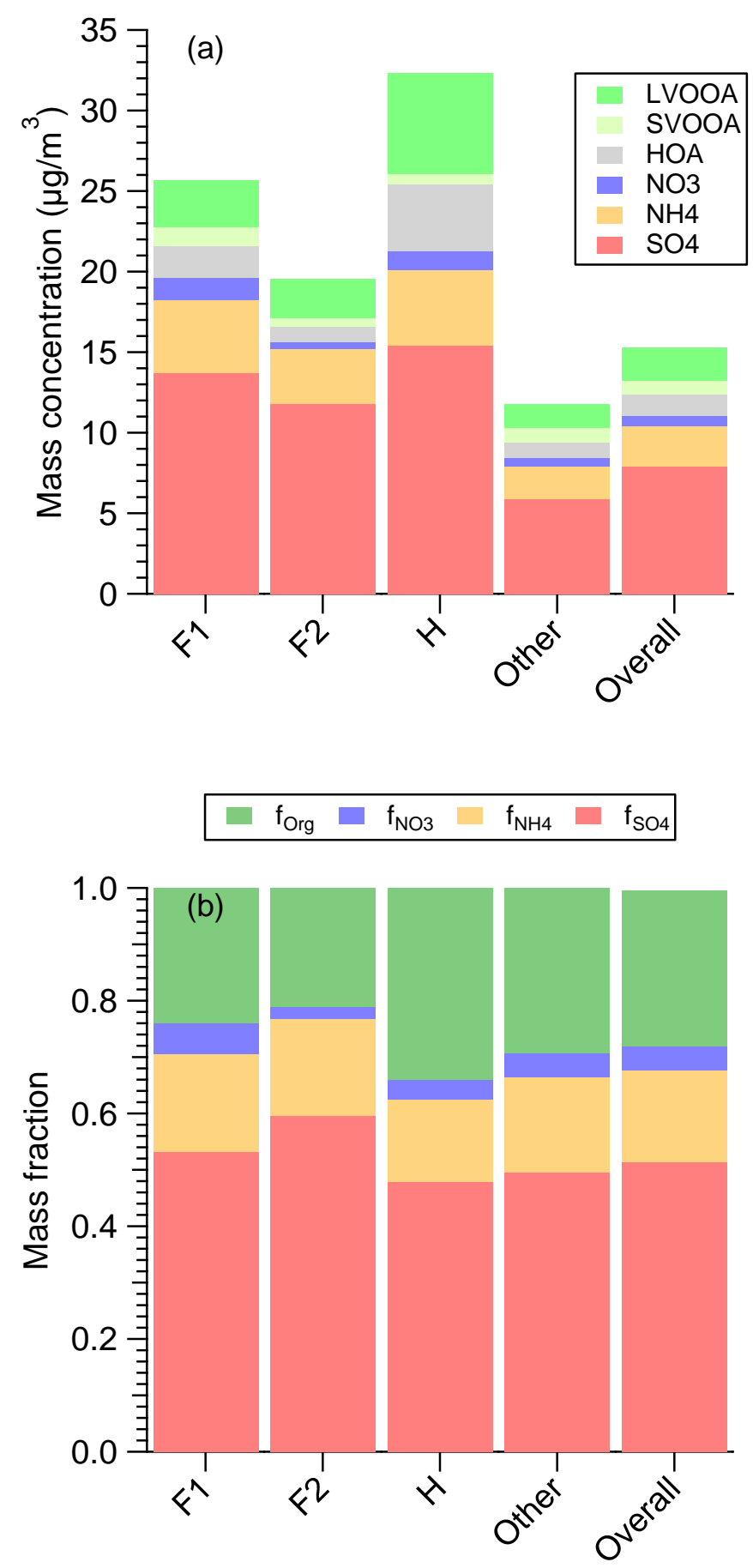

FIGURE S2. (a) Average mass concentrations of LVOOA, SVOOA, HOA, nitrate, ammonium and sulfate in five periods: foggy periods ( $F 1$ and $F 2$ ), hazy period $(H)$, non-foggy and non-hazy period ("other"), and overall period. (b) Average mass fractions of organics, nitrate, ammonium and sulfate in the five periods. 


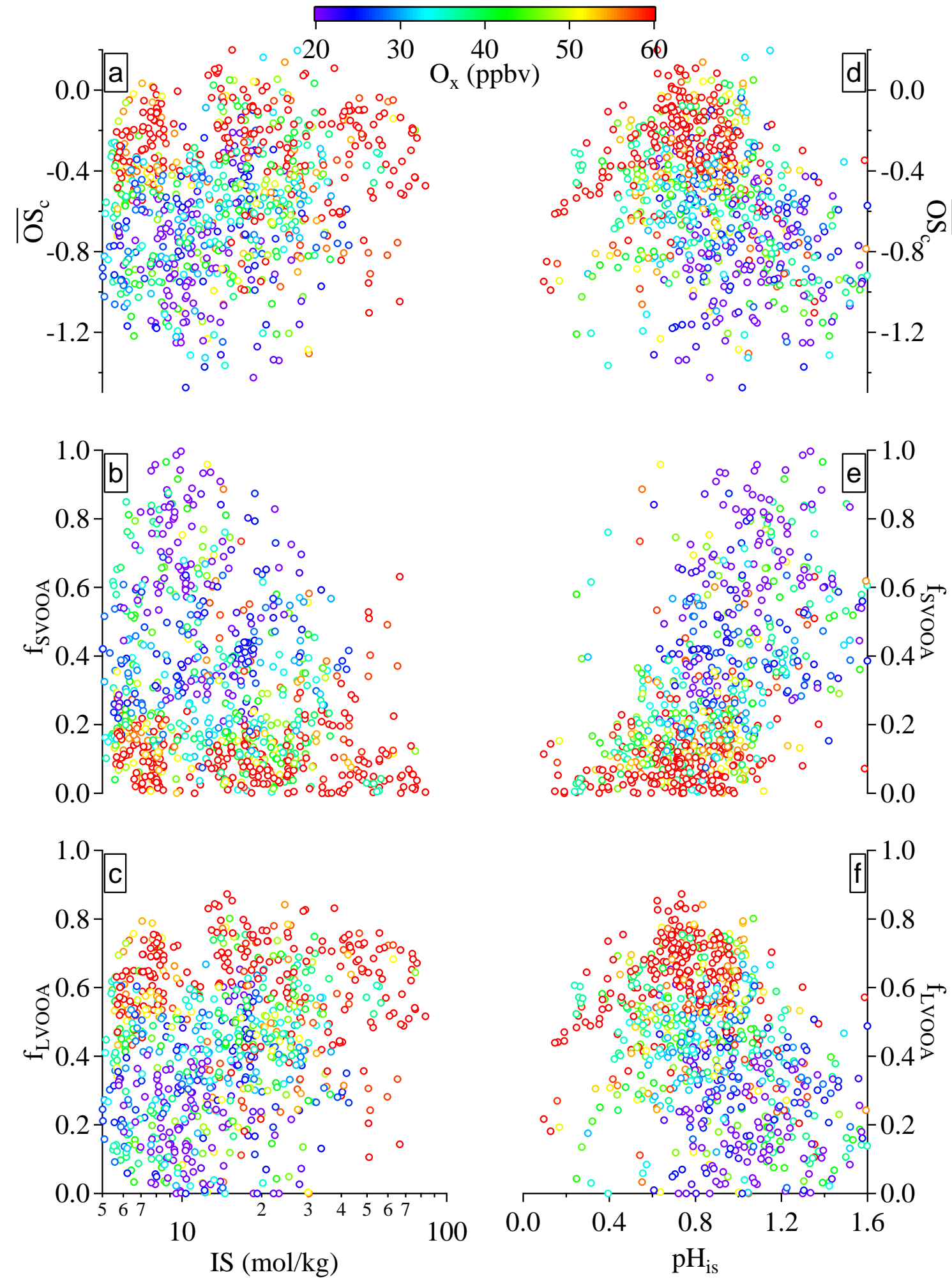

FIGURE S3. Hourly averaged carbon oxidation state $\left(\overline{\mathrm{OS}}_{\mathrm{c}}\right)(\mathrm{a})$, SVOOA fraction $\left(\mathrm{f}_{\mathrm{SVOOA}}\right)(\mathrm{b})$, and LVOOA fraction $\left(\mathrm{f}_{\mathrm{LVOOA}}\right)(\mathrm{c})$ plotted against estimated ionic strength (IS). Carbon oxidation state $\left(\overline{\mathrm{OS}}_{\mathrm{c}}\right)(\mathrm{d})$, SVOOA fraction $\left(\mathrm{f}_{\mathrm{SVOOA}}\right)(\mathrm{e})$, and LVOOA fraction $\left(\mathrm{f}_{\text {LVOOA }}\right)(\mathrm{f})$ plotted against estimated fine particle in situ $\mathrm{pH}$ $\left(\mathrm{pH}_{\mathrm{is}}\right)$. All data points are color coded according to $\mathrm{O}_{\mathrm{x}}$ concentration. 


\section{Positive matrix factorization (PMF)}

High-resolution mass spectral data were used to run the positive matrix factorization (PMF) analysis. PMF was run for 1 to 7 factors, with FPeak and Seed both set to 0 because little change was found for varying these two values. A three-factor solution was chosen based on $\mathrm{Q} / \mathrm{Q}_{\exp }$ values and mass spectral features. These two factors are hydrocarbon-like organic aerosol (HOA), semi-volatile organic aerosol (SVOOA), and low-volatility organic aerosol (LV-OOA). The mass fractions of these factors from PMF analysis of high-resolution mass spectral data were used directly, while they were multiplied by mass concentration of organics obtained by unit-mass-resolution data analysis when mass concentrations of these three factors were presented. 